\title{
Journal of Materials Chemistry
}

\section{PAPER}

1

The development of controllable complex curing agents for epoxy resinsPart 3. An investigation of the shelf life and thermal dissociation behaviour of bis(acetanilido)tris(acetato)dicuprate(II)

Ian Hamerton, Alan M. Emsley, John N. Hay, Henryk Herman, Brendan J. Howlin and Peter Jepson

A copper(II) complex, containing anthranilamide ligands, has been shown to display latent behaviour over a prolonged period of ambient temperature storage when formulated within MY721, a commercial epoxy resin recognised as an $\tilde{a}$ industry standardã. The onset of cure occurs just above 100 $\hat{\hat{o}} \mathrm{C}$ to yield a polymer with a dry $\mathrm{Tg}$ of $128 \hat{\tilde{C} \mathrm{C}}$.

Please check the proof of your paper carefully. Your proof will not be read in detail by staff after you have returned it to us. It is your responsibility to ensure that the proof has been read carefully.

Translation errors between word-processor files and typesetting systems can occur so the whole proof needs to be read even if an electronic file has been supplied. Please pay particular attention to: tabulated material (this may have been rekeyed); equations; numerical data; figures and graphics; and references. If you have not already indicated the corresponding author(s) please mark their name(s) with an asterisk. Please fax or e-mail your corrections to us. When returning the proof by fax please also include a list detailing the corrections to be made. If responding by e-mail please send only a list of corrections - do not make any changes directly to the pdf file.

This proof reflects the content and general style of the paper without the stylistic complexity of the final printed page; however, the only differences should be minor layout changes such as different line breaks, tables being double column instead of single column and improvements in graphic placement.

We will endeavour to publish the article electronically on the RSC web site as soon as possible after we receive your corrections. NB: No late corrections can be made hence please ensure that only your final corrections are notified to us.

Please return your final corrections, where possible within $\mathbf{4 8}$ hours of receipt, to:

Serials Production, The Royal Society of Chemistry,

Tel: +44 (0)1223 432345; Fax: +44 (0)1223 432160; E-mail: proofs@rsc.org

Reprints - Electronic (PDF) reprints will be provided free of charge to the corresponding author. Enquiries about purchasing paper reprints should be addressed to: Production Operations Department (prodops@rsc.org). Costs for reprints are below:

$\begin{array}{lrr}\text { Reprint costs } & \text { Cost for } 50 \text { copies } & \text { Cost for each additional } 50 \text { copies } \\ \text { No of pages } & £ 180 & £ 115 \\ 2-4 & £ 300 & £ 230 \\ 5-8 & £ 600 & £ 480 \\ 9-20 & £ 1100 & £ 870 \\ 21-40 & £ 1700 & £ 1455 \\ >40 & \\ \text { Cost for including cover of journal issue: } & \\ £ 50 \text { per 50 copies } & \end{array}$


1 The development of controllable complex curing agents for epoxy resins Part 3. $\uparrow$ An investigation of the shelf life and thermal dissociation behaviour of bis(acetanilido)-tris(acetato)dicuprate(II)

\author{
Ian Hamerton, ${ }^{* a}$ Alan M. Emsley, ${ }^{b}$ John N. Hay, ${ }^{a}$ Henryk Herman, ${ }^{b}$ Brendan J. Howlin ${ }^{a}$ and Peter Jepson ${ }^{a}$
}

Received 20th July 2005, Accepted 21st September 2005

First published as an Advance Article on the web

DOI: $10.1039 / b 510393 b$

Bis(acetanilido)-tris(acetato)dicuprate(II), $\left[\mathrm{Cu}_{2}\left(\mathrm{C}_{7} \mathrm{H}_{8} \mathrm{~N}_{2} \mathrm{O}\right)_{2}\left(\mathrm{CH}_{3} \mathrm{CO}_{2}^{-}\right)_{3}\right]$, is incorporated into MY721, a commercial epoxy resin recognised as an 'industry standard'. Infrared spectroscopy and thermogravimetry are employed to examine the structure and thermal dissociation behaviour of the newly prepared complex. Multivariate analysis techniques (e.g. principal components analysis) are used to examine the spectral data to corroborate the dissociation temperature. The shelf life and cure characteristics of the commercial epoxy/curing agent formulation are determined using differential scanning calorimetry and vibrational spectroscopy.

\section{Introduction}

The market for thermoset polymers is substantially smaller than the demand for thermoplastics, e.g. in 2003 the total consumption of thermoplastics in Western Europe was 38148000 tonnes, compared with 10640000 tonnes of thermosets. ${ }^{1}$ Despite this, epoxy resins still form a substantial market and in their consumption totals around 900000 tonnes in the USA, Western Europe and Asia/Pacific combined, with Asia taking a $35 \%$ share. ${ }^{2}$ The principal uses for epoxy resins are (in approximate order of consumption) surface (protective) coatings, electrical/electronic components, composites (reinforced resins), bonding and adhesives, flooring (construction) and tooling and casting.

The conversion of epoxy resins from liquid or semi-solid monomers into hard, infusible thermoset networks occurs via the introduction of cross-linking agents and the initiation of polymerisation by thermal, ultraviolet or microwave radiation, etc. Polyamines are among the most commonly used curing agents for epoxy resins and make up around $22 \%$ of the commercial market; ${ }^{3}$ primary, secondary and tertiary amines may all be used to initiate cure in epoxy systems. Primary and secondary amines are generally employed in stoichiometric amounts (as the amine becomes incorporated within the epoxy polymer network), but tertiary amines are used in catalytic quantities. Where tertiary amines are used, ring-opening of the oxirane group occurs prior to polymerization taking place via a polyetherification mechanism. The choice of amine governs the formation of polymer networks that differ in terms of their cross-link density, and hence glass transition temperature

\footnotetext{
${ }^{a}$ Chemistry Division, School of Biomedical and Molecular Sciences, University of Surrey, Guildford, Surrey, United Kingdom GU2 7XH. E-mail: i.hamerton@surrey.ac.uk; Fax: +441483 686851; Tel: +441483689587

${ }^{b}$ Polymer Research Centre, School of Biomedical and Molecular Sciences, University of Surrey, Guildford, Surrey, United Kingdom GU2 $7 X H$

$\uparrow$ For Parts 1 and 2, see refs. ? and?
}

which, in turn, has serious implications for the resin performance and ultimate application.

Epoxy resins are often formulated as 'one-pot' systems, which contain the monomer or prepolymer, curing agent(s) and additives, for sale or shipment. However, in order to formulate a curative system with a long shelf life (to enable storage either prior to shipment or between periods of use) each reactive component has to remain inert in the presence of any other co-reactants at the storage temperature. The curing agent may be rendered temporarily unreactive towards the epoxy group by complexation, thus preventing the lone pairs of electrons on the amino nitrogen atoms from participating in a nucleophilic attack. The association should be sufficiently strong to prevent premature reaction, but sufficiently labile to allow the initiation and polymerisation reactions to proceed, once a pre-determined cure temperature has been achieved.

Since the 1970s, transition metal complexes have been added to catalyse the reaction between curing agents and epoxy resins ${ }^{4}$ and their use has recently been reviewed. ${ }^{5}$ Our previous work has examined the potential of a variety of nitrogenous ligands, including complexes based on parent imidazoles ${ }^{6,7}$ and aromatic amines such as $o$-phenylene diamine (OPD) ${ }^{8}$ and 2-aminobenzylamine $(2-\mathrm{ABA})^{8,9}$ (containing aliphatic and aromatic amino functions). In these preceding papers we have outlined both the benefits and the potential drawbacks of the ligands employed and this paper details the latest work in this process, by seeking to exploit the beneficial properties of the anthranilamide ligand.

\section{Apparatus}

Differential scanning calorimetry (DSC) was carried out using a Perkin-Elmer DSC7 on samples (ca. $6 \pm 1 \mathrm{mg}$ ) over the range $30-300{ }^{\circ} \mathrm{C}$ at a range of heating rates $(5,10,15$ and $20 \mathrm{~K} \mathrm{~min}^{-1}$ ). Measurements were made under $\mathrm{N}_{2}$ $\left(40 \mathrm{~cm}^{3} \min ^{-1}\right)$ using sealed $30 \mu \mathrm{l}$ aluminium pans with a pierced lid. Glass transition temperatures $\left(T_{\mathrm{g}}\right)$ were determined by performing a rescan experiment $\left(10 \mathrm{~K} \mathrm{~min}^{-1}\right)$ directly after quenching and cooling the scanned sample. The apparent $T_{\mathrm{g}}$ is , 
1 quoted as the midpoint of the inflection in the baseline. The differential kinetic equations were solved by using a commercial software package (ModelMaker v3.0.4 from Cherwell Electronics). Thermogravimetry (TG) was performed using a Pyris $^{(\mathrm{m})}$ operated Perkin-Elmer TGA7 on samples (ca. $5 \pm$ $1 \mathrm{mg}$ ) at a fixed heating rate of $10 \mathrm{~K} \mathrm{~min}^{-1}$ between 50 and $1000{ }^{\circ} \mathrm{C}$. Measurements were made under flowing $\mathrm{N}_{2}$ $\left(40 \mathrm{~cm}^{3} \mathrm{~min}^{-1}\right)$ using a platinum boat. Mid infrared data were acquired using a Perkin-Elmer System 2000 FT-IR spectro-

10 meter using $\mathrm{KBr}$ disks and also an ATR accessory, which was placed in conjunction with a temperature controlled heating accessory. Spectra were obtained with a resolution of $4 \mathrm{~cm}^{-1}$ under strong apodisation, and 16 scans were co-added to improve the signal-to-noise ratio, at temperatures between 20 and $160{ }^{\circ} \mathrm{C}$. Near infrared (NIR) spectra were acquired by placing a sample, comprising a blend of MY721 and the anthranilamide complex, between microscope cover slips in a temperature controlled heating accessory. This was placed in the sample compartment of a Perkin-Elmer System 2000 FT-

20 NIR spectrometer. Spectra were acquired at 15 min intervals (corresponding to a heating rate of $0.1 \mathrm{~K} \mathrm{~min}^{-1}$ ) with a resolution of $4 \mathrm{~cm}^{-1}$ under strong apodisation, and 32 scans were co-added to improve the signal-to-noise ratio, at temperatures between $60{ }^{\circ} \mathrm{C}$ and $150{ }^{\circ} \mathrm{C}$. Magnetic susceptibility data were acquired using a Stanton Instruments SM12 Gouy balance: samples were placed in a cylindrical glass vessel and suspended in a non-homogeneous magnetic field and the application of a current ( $1 \mathrm{~A}$ ) induced an increase or decrease in the sample weight. Elemental analysis was performed on samples (1-2 mg) using an Exeter Analytical EA440 CHN/O/S elemental analyser by combusting the samples in oxygen in a high temperature furnace $\left(1800{ }^{\circ} \mathrm{C}\right)$ using helium as the carrier gas.

\section{Materials}

Copper(II) acetate tetrahydrate and anthranilamide were obtained from Aldrich Chemical Corp. The commercial epoxy (MY721) was obtained from Ciba-Geigy products and its epoxy equivalent weight (EEW) was determined to be $119.70 \mathrm{~g}$ using an in-house (Cytec-Fiberite Ltd., Wrexham) titrimetric method (hydrochloric acid $0.44 \mathrm{~N}$, bromophenol blue). All commercial materials gave acceptable analytical results and were consequently used without further purification unless otherwise stated in the text.

\section{Preparation of bis(acetanilido)-tris(acetato)dicuprate(II)}

Copper(II) acetate tetrahydrate $(0.01 \mathrm{~mol})$ was dissolved in ethanol $\left(100 \mathrm{~cm}^{3}\right)$ in a $500 \mathrm{~cm}^{3}$ three necked round bottomed flask and heated with constant stirring to $40{ }^{\circ} \mathrm{C}$. Anthranilamide $(0.02 \mathrm{~mol})$ was dissolved in ethanol $\left(50 \mathrm{~cm}^{3}\right)$ and added dropwise to the solution with constant stirring over a period of 15 minutes. The resulting precipitate was filtered and washed three times with ethanol $\left(3 \times 50 \mathrm{~cm}^{3}\right)$ to produce a light green solid (yield 92\%) of melting point greater than $230{ }^{\circ} \mathrm{C}$ and $\mu_{\text {eff }} 1.29$ B.M. Elemental analysis calculated for $\mathrm{C}_{22} \mathrm{H}_{33} \mathrm{~N}_{4} \mathrm{O}_{10} \mathrm{Cu}_{2}$ (i.e. a dimer, containing one molecule of water and one molecule of ethanol of crystallization) $40.93 \%$ C, $5.11 \% \mathrm{H}, 8.68 \% \mathrm{~N}$; found $41.35 \% \mathrm{C}, 4.44 \% \mathrm{H}, 8.57 \% \mathrm{~N}$.

\section{Procedure for the formulation of complex-epoxy resin mixture}

The amount of curing agent incorporated in the epoxy formulations was based on the EEW of the commercial monomer and the number of active amino hydrogen atoms in the dimeric complex. $\left[\mathrm{Cu}_{2}\left(\mathrm{C}_{7} \mathrm{H}_{8} \mathrm{~N}_{2} \mathrm{O}\right)_{2}\left(\mathrm{CH}_{3} \mathrm{CO}_{2}{ }^{-}\right)_{3}\right]$ has a relative molar mass of $576 \mathrm{~g} \mathrm{~mol}^{-1}$ and contains 8 active hydrogen atoms and one mole of active hydrogen atoms represents $72 \mathrm{~g}(576 \div 8)$ : the stoichiometric equivalent of the EEW. Hence, for every $119.70 \mathrm{~g}$ of MY721, $72 \mathrm{~g}$ of $\left[\mathrm{Cu}_{2}\left(\mathrm{C}_{7} \mathrm{H}_{8} \mathrm{~N}_{2} \mathrm{O}\right)_{2}\left(\mathrm{CH}_{3} \mathrm{CO}_{2}{ }^{-}\right)_{3}\right]$ are required and this curing agent loading was used for the subsequent spectral and thermal measurements.

\section{Results and discussion}

\section{Rationale behind the selection of the ligand}

During previous work to examine potential curing agents containing $\mathrm{OPD}^{8}$ and 2-ABA ligands, ${ }^{8,9}$ it was observed that the formulated curing agents displayed excellent shelf lives (of the order of 67 days at room temperature when mixed in MY721) and were able to effect cure in commercial epoxy resins within reasonable timescales. However, the volatility of the curing agents during the cure process, observed during rheological measurements, caused voids in the curing resins, as the liberated ligands underwent volatilisation, but were entrapped in the gelling mixture. This phenomenon, if translated to cured composite specimens, would obviously compromise the mechanical properties of the polymer and rendered the curing agents of limited use.

Anthranilamide has similar binding characteristics to the previous ligands, but has a higher melting point $\left(\mathrm{ca} .114^{\circ} \mathrm{C}\right)$ than 2-ABA and OPD and should not volatilise when undergoing dissociation from the metal centre. To prolong the shelf life, the polydentate ligand should coordinate as completely as possible, in this case via the nitrogen of the amine and the oxygen and/or nitrogen of the amide group. The latter is electron withdrawing and should reduce the ability of the amido nitrogen to co-ordinate to the metal centre, consequently leading to a reduction in the temperature at which the amido-metal bond is broken. The selection of a commercial material is also important to keep costs down.

\section{Evidence for the structure of the complex prepared during this study}

Allan et al. carried out, ${ }^{10,11}$ thermal, structural and electrical studies on chloro complexes of $\mathrm{Co}(\mathrm{II}), \mathrm{Ni}$ (II) and $\mathrm{Cu}(\mathrm{II})$ containing anthranilamide ligands and their data suggested that the ligand complexed through the amino nitrogen and the amido oxygen when introduced to $\mathrm{Ni}$ (II) and $\mathrm{Co}$ (II), but only through the amino nitrogen when introduced to $\mathrm{Cu}(\mathrm{II})$. In the present study, model ligands anthranilamide and aniline were examined to determine whether complexation was occurring through the amino or amido groups (or both). The amine bending bands are in close proximity to those of the amide, although the $\delta_{\mathrm{N}-\mathrm{H}}$ bands of aniline are found at slightly lower wave numbers $\left(1619 \mathrm{~cm}^{-1}\right.$ and $\left.1601 \mathrm{~cm}^{-1}\right)$.

There is general consensus concerning the assignment of amido bands in the mid-infrared. Kemp ${ }^{12}$ has studied the 


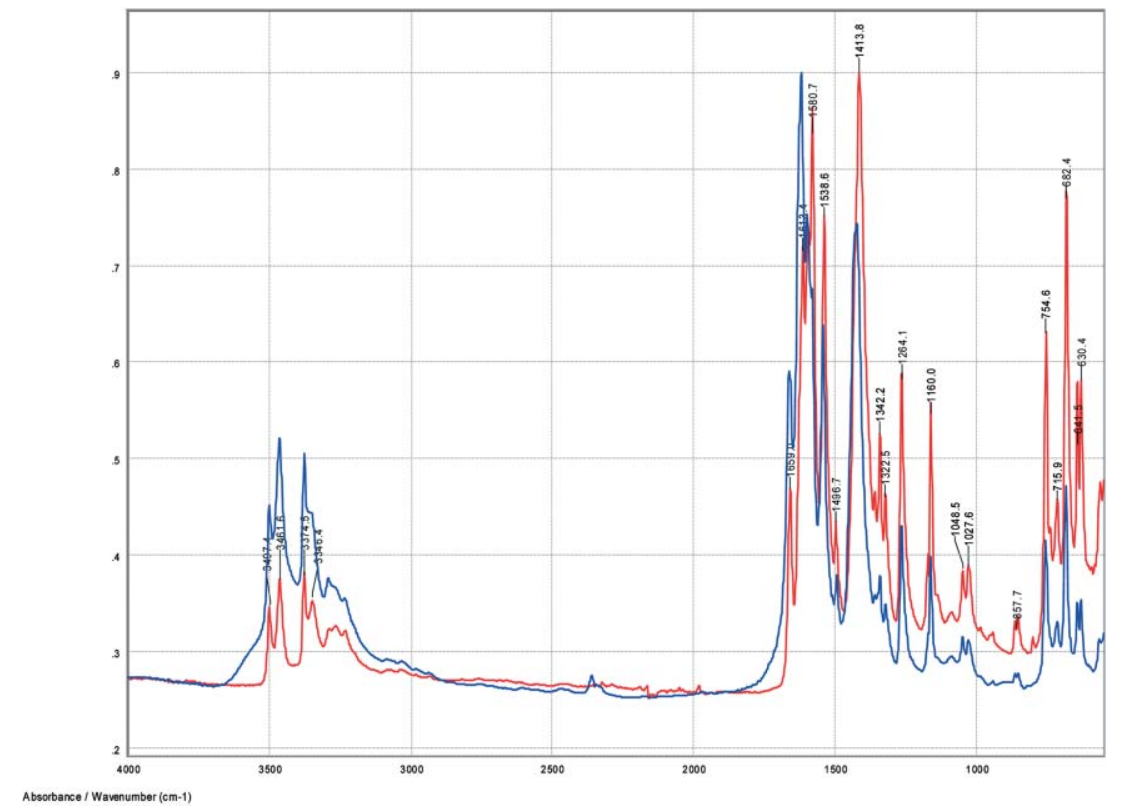

Fig. 1 Infrared absorption spectrum of bis(acetanilido)-tris(acetato)dicuprate(II) in KBr (blue) and analysed using ATR (red).

bands in the spectrum of benzamide and stated that there are two sets of bands that are characteristic of primary amides, $v_{\mathrm{N}-\mathrm{H}}$ near $3400 \mathrm{~cm}^{-1}$ and $3200 \mathrm{~cm}^{-1}$ and $v_{\mathrm{C}=\mathrm{O}}$ (amide I) and $\delta_{\mathrm{N}-\mathrm{H}}$ (amide II) which occur at around $1650 \mathrm{~cm}^{-1}$ (and the data presented in Fig. 1 and Table 1 agree with these assignments). Weast and Grasselli ${ }^{13}$ also describe the $v_{\mathrm{N}-\mathrm{H}}$ for the amide to be at $3448 \mathrm{~cm}^{-1}$ and $3226 \mathrm{~cm}^{-1}$ and $\delta_{\mathrm{N}-\mathrm{H}}$ $1639 \mathrm{~cm}^{-1}$ for both the anthranilamide and the benzamide (with a shift to higher wave numbers for the $v_{\mathrm{C}=\mathrm{O}}$ in the anthranilamide). Lin-Vien et al. ${ }^{14}$ state that unsubstituted amides in the hydrogen bonded state have asymmetric $\mathrm{NH}_{2}$ stretch bands near $3350 \mathrm{~cm}^{-1}$ and symmetric $\mathrm{NH}_{2}$ stretch bands near $3180 \mathrm{~cm}^{-1}$. The $\mathrm{C}=\mathrm{O}$ stretch band $(1680$ $1640 \mathrm{~cm}^{-1}$ ) and the $\mathrm{NH}_{2}$ scissors deformation band (1640$1620 \mathrm{~cm}^{-1}$ ) overlap in the hydrogen bonded state, with the former being the more intense of the two bands in the IR.

Table 1 contains the assignments that Allan et al. reported for three complexes of anthranilamide and the data for the newly-prepared complex. These suggest that the $v_{\mathrm{N}-\mathrm{H}}\left(\mathrm{NH}_{2}\right)$ band has some similarities to those bands reported for free anthranilamide, whilst those for $v_{\mathrm{N}-\mathrm{H}}\left(\mathrm{CONH}_{2}\right)$ are somewhat higher than the values quoted for the copper, cobalt and nickel complexes reported by Allan et al. The $v_{\mathrm{C}=\mathrm{O}}$ band of the new complex is also closer to the value observed for those complexes containing bidentate anthranilamide,${ }^{10}$ suggesting that, in contrast with the findings of Allan et al., our complex contains monodentate anthranilamide ligands bonded to the copper through the amido nitrogen, with the ligands bearing free primary aryl amines. Consequently, future studies might involve e.g. cobalt in order to increase the likelihood of achieving full complexation.

Having ascertained the denticity of the ligands, it was necessary to determine whether the complexes were polymeric. Magnetic susceptibility values for $\mathrm{Cu}(\mathrm{II})$ complexes in an octahedral environment tend to lie between 1.75 and 2.20 B.M. regardless of symmetry and at normal temperatures ${ }^{15}$ and $\left[\mathrm{Cu}(2-\mathrm{ABA})_{3} \mathrm{Cl}_{2}\right]$ and $\left[\mathrm{Cu}(2-\mathrm{ABA})_{3} \mathrm{Cl}_{2}\right]$ yield $\mu_{\text {eff }}$ values of 2.90-2.91 B.M. and 1.82-1.84 B.M. respectively. ${ }^{716} \mathrm{~A} \mu_{\text {eff }}$ value of 1.29 B.M. was obtained for the newly-prepared complex, suggesting that the $\mathrm{Cu}$ (II) metal centre is in a polymeric or bi-nuclear environment with $\mathrm{Cu}-\mathrm{Cu}$ interactions. These data lead to a possible structure for the complex in which the acetate ligands bridge the bi-nuclear centre and in which two anthranilamide ligands are coordinated via the amido nitrogen atoms, thus leaving a free amino group on each ligand. Similar structures are also possible in which the aromatic amine is coordinated to the metal centre (or a mixture of the two).

Table 1 Selected infrared spectral assignments of model compounds and selected complexes containing anthranilamide $\left(\mathrm{C}_{7} \mathrm{H}_{8} \mathrm{~N}_{2} \mathrm{O}\right)$

\begin{tabular}{lllll}
\hline Compound & $v_{\mathrm{N}-\mathrm{H}}\left(\mathrm{NH}_{2}\right)$ & $v_{\mathrm{N}-\mathrm{H}}\left(\mathrm{CONH}_{2}\right)$ & $v_{\mathrm{C}-\mathrm{O}}\left(\mathrm{CH}_{3} \mathrm{CO}_{2}{ }^{-}\right)$ & $v_{\mathrm{C}=\mathrm{O}}$ \\
\hline Anthranilamide* & $3406(\mathrm{~s}) 3316(\mathrm{~s})$ & $3378(\mathrm{~s}) 3192(\mathrm{~s})$ & - & $1656(\mathrm{~s})$ \\
Benzamide & - & $3368(\mathrm{~s}), 3173(\mathrm{~s})$ & - & - \\
Benzylamine & 3371 (s) $3290(\mathrm{~s})$ & - & - & - \\
Aniline $\left(10 \%\right.$ in $\left.\mathrm{CCl}_{4}\right)$ & $3475(\mathrm{~s}) 3392(\mathrm{~s})$ & - & - & $1658(\mathrm{~s})$ \\
{$\left[\mathrm{Cu}\left(\mathrm{C}_{7} \mathrm{H}_{8} \mathrm{~N}_{2} \mathrm{O}\right)_{2} \mathrm{Cl}_{2}\right]^{*}$} & $3370(\mathrm{~s}) 3317(\mathrm{~s})$ & $3230(\mathrm{~s}) 3180(\mathrm{~s})$ & - & $1668(\mathrm{~s})$ \\
{$\left[\mathrm{Co}\left(\mathrm{C}_{7} \mathrm{H}_{8} \mathrm{~N}_{2} \mathrm{O}\right)_{2} \mathrm{Cl}_{2}\right]^{*}$} & $3382(\mathrm{~s}) 3306(\mathrm{~s})$ & $3236(\mathrm{~s}) 3183(\mathrm{~s})$ & - & $1642(\mathrm{~s})$ \\
{$\left[\mathrm{Ni}_{7}\left(\mathrm{C}_{7} \mathrm{H}_{8} \mathrm{~N}_{2} \mathrm{O}\right)_{2} \mathrm{Cl}_{2}\right]^{*}$} & $3372(\mathrm{~s}) 3312(\mathrm{~s})$ & $3220(\mathrm{~s}) 3182(\mathrm{~s})$ & - & $1659(\mathrm{~s})$
\end{tabular}

${ }^{a} \mathrm{~s}=$ strong, $\mathrm{m}=$ medium, $\mathrm{w}=$ weak, ot $=$ overtone, ${ }^{*}=$ data originally reported in ref. $9,-=$ not present in compound. 
1 Determination of shelf life of the epoxy-complex formulation using thermal analysis

Thermal analysis can give a good indication of shelf life over an extended period of storage ${ }^{17}$ by monitoring changes in polymerisation enthalpy and indirectly the extent of reaction. A blend of MY721 with the new complex was prepared and it was noticeable that bis(acetanilido)-tris(acetato)dicuprate(II) showed greater solubility in the epoxy formulations than e.g. OPD, presumably as a result of the interaction between the polar amine/carbonyl groups with the glycidyl amine groups; no precipitation was observed during prolonged room temperature storage. The thermal behaviour of blends of MY721 and the complex were examined using scanning DSC and the data are presented in Table 2 and Fig. 2.

The thermogram of the newly-formulated mixture (acquired at a heating rate of $10 \mathrm{~K} \mathrm{~min}^{-1}$ ) is shown in the "Day 0" entry of Fig. 3. Over a period of 70 days, the formulated samples were stored at ambient temperature and analysed periodically via dynamic scan $\left(10 \mathrm{~K} \mathrm{~min}^{-1}\right)$ between $30{ }^{\circ} \mathrm{C}$ and $300{ }^{\circ} \mathrm{C}$ to monitor the effects of storage on the magnitude and the onset temperature of the polymerisation exotherm. A plot of the variation in the polymerization enthalpy is depicted in Fig. 3 and aside from some outliers (exacerbated by a reducing enthalpy and an increasingly 'noisy' baseline as storage progressed), a general downward trend is observed. The prolonged storage does show evidence of increasing ambient cure, although this is not dramatic despite the length of the storage period. In comparison with OPD and 2-ABA based complexes, ${ }^{8}$ the presence of uncoordinated amino species in the complex reduced the overall stability of these complexes in the epoxy resins.

The spectroscopic data for the complex suggested that the two anthranilamide ligands are only monodentate within the dimeric complex, thus leaving a free amino group available on each ligand able to react with the epoxy resin. This is clearly less desirable than e.g. OPD or 2-ABA, in which complete association was achieved, but it was decided to assess the effect of the free amino groups on storage stability nonetheless.

Blends of bis(acetanilido)-tris(acetato)dicuprate(II) and MY721 display similar thermal behaviour to that reported ${ }^{8}$ for $\left[\mathrm{Ni}(\mathrm{OPD})_{3} \mathrm{Cl}_{2}\right]$ or $\left[\mathrm{Cu}(2-\mathrm{ABA})_{2} \mathrm{Cl}_{2}\right]$. The DSC thermogram of the complex (shown in Fig. 2a as the uppermost

Table 2 Thermal analysis of an unaged MY721/[Cu $\left(\mathrm{Cu}_{2} \mathrm{H}_{8} \mathrm{~N}_{2} \mathrm{O}\right)_{2}$ $\left.\left(\mathrm{CH}_{3} \mathrm{CO}_{2}^{-}\right)_{3}\right]$ formulation (at $t=$ zero days) undertaken using DSC (at $10 \mathrm{~K} \mathrm{~min}^{-1}$, under flowing nitrogen)

\section{Heating}

rate/ $/ \mathrm{K} \mathrm{min}^{-1} \quad$ Cure onset ${ }^{a} /{ }^{\circ} \mathrm{C} \quad T_{\max } /{ }^{\circ} \mathrm{C}^{b} \quad \Delta H / \mathrm{J} \mathrm{g}{ }^{-1 c} \quad T_{\mathrm{g}} /{ }^{\circ} \mathrm{C}^{d}$

\begin{tabular}{rllll}
\hline 20 & 145 & 158 & 497 & 128 \\
15 & 140 & 153 & 523 & - \\
10 & 134 & 146 & 529 & - \\
5 & 123 & 136 & 508 & -
\end{tabular}

${ }^{a}$ The cure onset is quoted as the point at which the exothermic peak rises from the baseline. ${ }^{b}$ DSC analysis reveals a large exotherm with the $T_{\max }$ tabulated and several less well-defined shoulders at higher temperatures. ${ }^{c}$ The individual exothermic processes were poorly resolved and so a total value ( $\mathrm{J} \mathrm{g}^{-1}$ of formulation: epoxy + curing agent) is quoted. ${ }^{d}$ Glass transition temperature quoted as the midpoint of the transition after rescan experiment. (a)

Shelf Life of $\mathrm{Cu}(\mathrm{Anth}) .(\mathrm{ac})_{2}$ in MY721 over one week

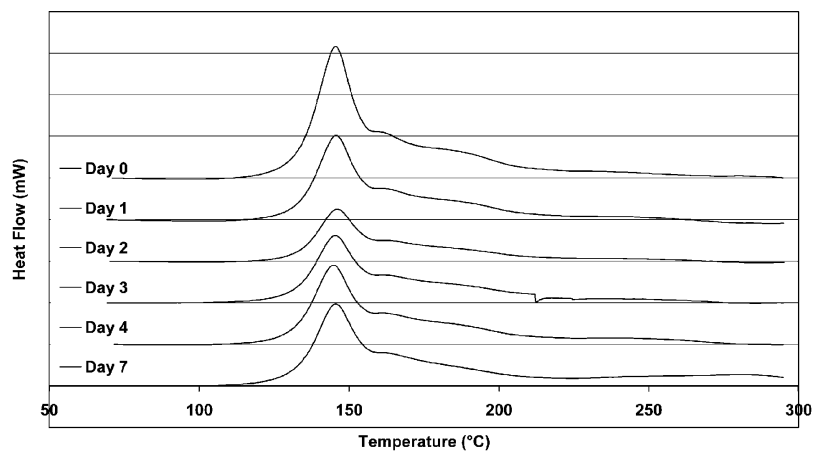

(b)

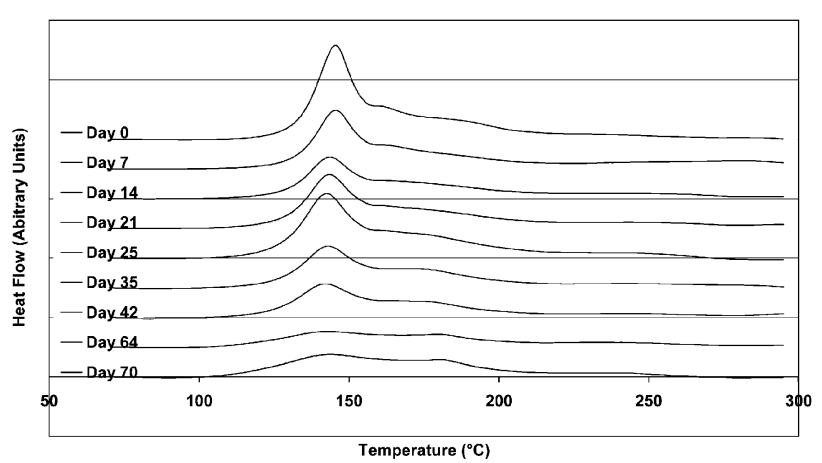

Fig. 2 DSC thermograms (exothermic flow upwards) obtained at $10 \mathrm{~K} \mathrm{~min}^{-1}$ under flowing nitrogen during prolonged storage at ambient temperature for an $\mathrm{MY} 721 /\left[\mathrm{Cu}_{2}\left(\mathrm{C}_{7} \mathrm{H}_{8} \mathrm{~N}_{2} \mathrm{O}\right)_{2}\left(\mathrm{CH}_{3} \mathrm{CO}_{2}{ }^{-}\right)_{3}\right]$ blend.

thermogram) reveals one major exothermic peak, although it does have less prominent shoulders between $160{ }^{\circ} \mathrm{C}$ and $280^{\circ} \mathrm{C}$. The latter are presumably due to the reactions of the (liberated) amido nitrogen or carbonyl oxygen with the epoxy ring; the acetato ligand and the epoxy and, ultimately,

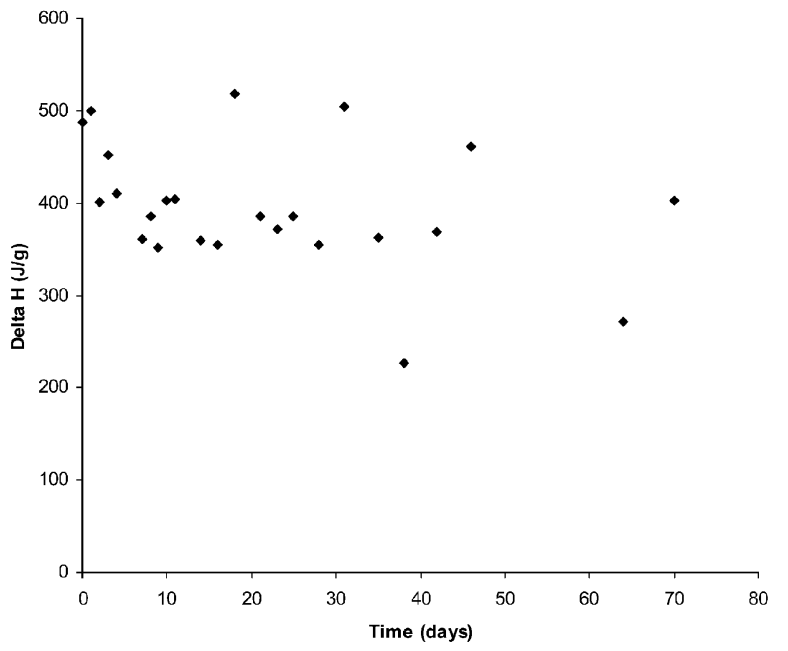

Fig. 3 Plots of polymerization enthalpy $(\bullet)$ from DSC data versus ambient storage time for an $\mathrm{MY} 721 /\left[\mathrm{Cu}_{2}\left(\mathrm{C}_{7} \mathrm{H}_{8} \mathrm{~N}_{2} \mathrm{O}\right)_{2}\left(\mathrm{CH}_{3} \mathrm{CO}_{2}{ }^{-}\right)_{3}\right]$ blend. 
polyetherification of the epoxy group. During the first week of the extended storage study, there was only a slight decrease $(<1 \mathrm{~K})$ in the temperature of the cure onset, although this is probably not significant within the somewhat limited precision of a scanning DSC experiment. In contrast, the initial cure onset temperature decreased by $4 \mathrm{~K}$ after 28 days and by $20 \mathrm{~K}$ after 64 days (although the position of the peak maximum did not change significantly over the 70-day period, with only a shift of around $2-3 \mathrm{~K}$ being observed). Over the same period of time the $\Delta H$ had decreased to around $25 \%$ of its initial value, but remained quite constant during the remaining 69 days.

A rescan was performed during each DSC experiment in order to determine the dry $T_{\mathrm{g}}$. The value for MY721 cured with bis(acetanilido)-tris(acetato)dicuprate(II) was initially $128{ }^{\circ} \mathrm{C}$ and displayed an initial drop of $23 \mathrm{~K}$ during the first day of storage, but thereafter remained practically constant during the remaining 69-day period (the last $T_{\mathrm{g}}$ recorded was $98{ }^{\circ} \mathrm{C}$ ). It should be borne in mind that this $T_{\mathrm{g}}$ represents a single scan in the DSC instrument and is not representative of a cure schedule optimised for use at elevated temperatures.

\section{Investigating the thermal dissociation behaviour of the complex}

We recognize that the use of thermogravimetry (TG) to determine the dissociation of a complex within an epoxy formulation should be treated with caution as the measurements may not represent the behaviour of the complex within an epoxy matrix. The data from the present TG experiments are presented in Table 3: bis-(acetanilido)-tris(acetato)dicuprate(II) appeared to degrade before reaching a melting point $\left(>230{ }^{\circ} \mathrm{C}\right)$. The dynamic TG data obtained showed a dissociation pattern over a large temperature range $(160$ $\left.1000{ }^{\circ} \mathrm{C}\right)$ with the initial mass loss $(45 \%)$ occurring at $210^{\circ} \mathrm{C}$ $\left(24 \% \mathrm{~min}^{-1}\right)$. The complex was apparently stable below $160^{\circ} \mathrm{C}$ with no drop in mass, indicating the absence of residual solvent in the sample. Using TG and differential thermal analysis, anthranilamide has been found ${ }^{10}$ to be thermally stable in the range $20-140{ }^{\circ} \mathrm{C}$ with pyrolytic decomposition commencing at $148{ }^{\circ} \mathrm{C}$ and total elimination of the sample occurring by $420{ }^{\circ} \mathrm{C}$.

However, TG is only semi-quantitative, due to the lack of a coupled detection method, such as mass spectrometry, gas chromatography or infrared spectroscopy, to observe which species are being released at the specified temperature. Consequently, at an early stage it was decided to use a combination of both infrared spectroscopy and thermal methods in order to determine the dissociation temperatures for the ligands.

Table 3 TG analysis of bis(acetanilido)-tris(acetato)dicuprate(II) performed under flowing nitrogen at $10 \mathrm{~K} \mathrm{~min}^{-1}$

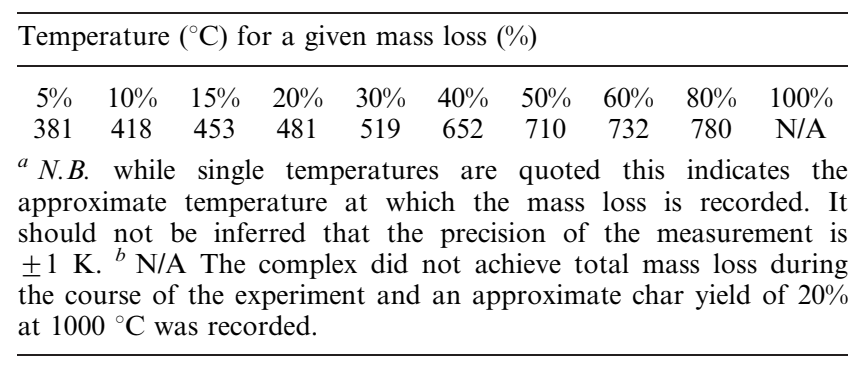

In a separate experiment, the complex was heated from room temperature to $150{ }^{\circ} \mathrm{C}$ and an FT-IR spectrum taken at $10 \mathrm{~K}$ intervals (Fig. 4). Additional information was provided by subjecting the spectral data to principal components analysis (PCA), a multivariate analysis technique, ${ }^{17}$ which utilises all the data and uses a holistic approach to determine similar and dissimilar spectra. The extraction of the principal components (PCs), which account for the variance in data, enables the particular analysis to be simplified, but makes no suppositions about the chemical meaning of the data. This technique has been shown ${ }^{19}$ to yield useful information in the correlation of infrared spectra of cyanate ester/bismaleimide blends with thermo-mechanical properties and has also been employed ${ }^{9}$ to probe the mechanism by which our previous complexes have undergone dissociation.

PCA was performed on the spectral data and it was found that three PCs account for $99.9 \%$ of the variation in the data (Fig. 5). A plot of PC1 (accounting for 87.1\%) vs. PC2 (accounting for $7.0 \%$ ) shows regular incremental changes in the data until $c a .130{ }^{\circ} \mathrm{C}$ at which point there is a large change in the plot, indicating that a significant change in the complex is occurring at this point.

Most of the spectral changes observed during the experiment occur in regions associated with both amino and amido groups (3100-3500 $\mathrm{cm}^{-1}$ and $1550-1690 \mathrm{~cm}^{-1}$ ). The main band changes, from the regression coefficient with temperature, are reductions at 3500, 3460, 3378, 1662, 1621, 1581, 1541 and $1267 \mathrm{~cm}^{-1}$. The overall reduction in the intensity of the amino and amido $\left(3100-3500 \mathrm{~cm}^{-1}\right)$ peaks upon heating is consistent with the ligands undergoing dissociation and volatilisation. To simulate the action of the complex within an epoxy formulation, a second series of spectroscopic experiments was performed using near infrared (NIR) spectroscopy on an epoxy formulation containing the complex and this is discussed later.

\section{Kinetic analysis of the thermal polymerisation behaviour of the epoxy/curing agent formulation during ambient storage}

We have previously examined the kinetics of both polymerisation and degradation processes involved with polycyanurates directly from differential equations..$^{20,21}$ In this approach, the polymer is assumed to consist of a number of reactive species, reacting independently of each other to form a single product by simple Arrhenius kinetics with activation energies and orders of reactions of $A_{1}, E_{1}, n_{1}, A_{2}, E_{2}, n_{2}$, etc.

We can thus write the kinetic equation for the $i$ th process as:

$$
k_{i}=A_{i} e^{\frac{-E_{i}}{R T}}
$$

where $k_{\mathrm{i}}$ is the rate constant at absolute temperature $T$ and $R$ is the universal gas constant.

The rate of reaction at temperature $T$ is then:

$$
\frac{d\left(\text { reactant }_{i}\right)}{d t}=k_{i}\left[\text { reactant }_{i}\right]^{n_{i}}
$$

Differentiating eqn. (1) with respect to temperature gives:

$$
\frac{d k_{i}}{d T}=\frac{E_{i}}{R T^{2}} A_{i} e^{\frac{-E_{i}}{R T}}=\frac{E_{i}}{R T^{2}} \cdot k_{i}
$$



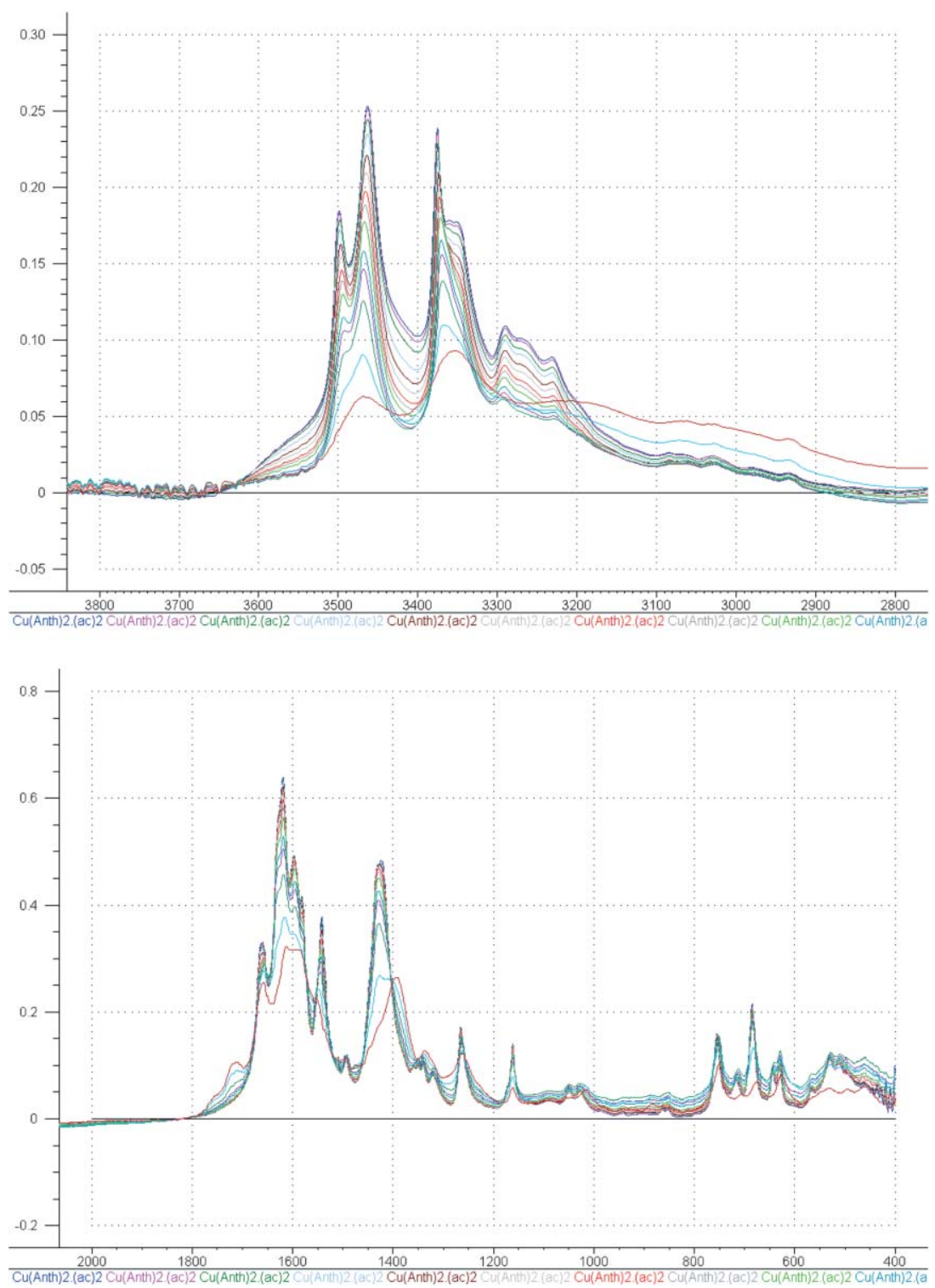

Fig. 4 Individual absorption spectra (showing selected regions) for bis(acetanilido)-tris(acetato)dicuprate(II) acquired at different temperatures.

and, if we plot extent of reaction against temperature, we can use the relationship $\frac{d T}{d t}=1$ (i.e. assuming a linear heating rate in the DSC) to solve eqns. (2) and (3) simultaneously for any number of concurrent processes, using numerical methods.

The formulation containing MY721 and bis(acetanilido)tris(acetato)dicuprate(II) was analyzed using DSC at a variety of heating rates and each data set was therefore treated individually to obtain the best fits to the data with the minimum number of equations, using an arbitrary linear baseline, which is reasonable in this case, since we see little evidence of baseline drift in the experimental data. The results are given in Table 4 and an example of the best fits to the DSC raw data is shown in Fig. 6.

In practice, the minimum number of processes required to fit the DSC data turned out to be four and the kinetic analysis allows these four processes to be compared with polymerizations of other epoxy formulations (Table 5). From a comparison of the Arrhenius parameters in Table 5, it is immediately noticeable that the figures for the first process (a near second order process, with mean activation energy $370 \mathrm{~kJ} \mathrm{~mol}^{-1}$ ) are unusually high for a typical amine-epoxy cure, suggesting that this initial step could incorporate both the dissociation of the coordinated ligand (e.g. the primary amido nitrogen) and the amide-epoxy co-reaction. For instance, a study ${ }^{22}$ of DER332 (a bisphenol diglycidyl ether) cured with dicyandiamide (cyanoguanidine or DICY) yielded a near first order process with an activation energy of $101 \mathrm{~kJ} \mathrm{~mol}^{-1}$. Admittedly, this is a complex cure process as the DICY molecule $\left(\mathrm{C}_{2} \mathrm{H}_{4} \mathrm{~N}_{4}\right)$ contains amino, amido and cyano groups and the high activation energy results partly from the requirement for the material to melt $\left(\mathrm{mp}>150{ }^{\circ} \mathrm{C}\right)$ prior to reaction. This is analogous to the need to effect thermal dissociation of the complex before full cure can take place, again resulting in high activation energies. 

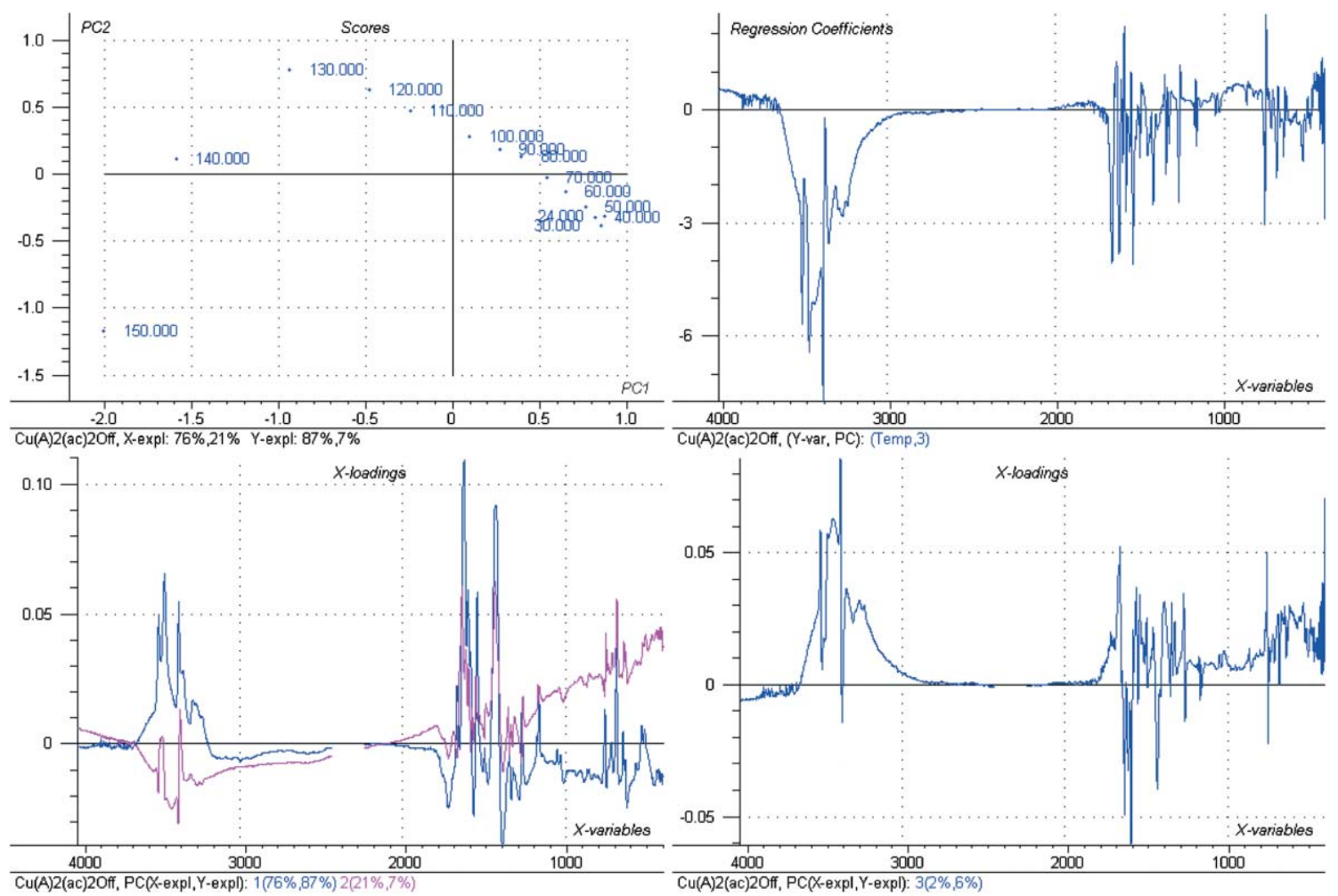

Fig. 5 PCA for bis(acetanilido)-tris(acetato)dicuprate(II) showing (anticlockwise, from bottom left) the two largest PCs, the third PC, the overall regression coefficient for temperature, and a plot of $\mathrm{PC} 2$ against $\mathrm{PC} 1$ showing the discontinuity at $130{ }^{\circ} \mathrm{C}$.

Table 4 Arrhenius kinetic parameters for the thermal polymerization of an unaged $\mathrm{MY} 721 /\left[\mathrm{Cu}_{2}\left(\mathrm{C}_{7} \mathrm{H}_{8} \mathrm{~N}_{2} \mathrm{O}\right)_{2}\left(\mathrm{CH}_{3} \mathrm{CO}_{2}{ }^{-}\right)_{3}\right]$ formulation $($ at $t=$ zero days)

\begin{tabular}{lllllll}
\hline Parameter & \multicolumn{2}{l}{ DSC heating rate/K min } \\
\hline & 5 & 10 & 15 & 20 & Mean value & Standard deviation \\
$A_{1}$ & $3.53 \times 10^{47}$ & $2.29 \times 10^{45}$ & $2.47 \times 10^{43}$ & $6.56 \times 10^{45}$ & $9.05 \times 10^{46}$ & $1.75 \times 10^{47}$ \\
$E_{1}$ & 374 & 367 & 357 & 380 & 370 & 10 \\
$n_{1}$ & 1.70 & 1.45 & 1.43 & 1.49 & 1.52 & 0.12 \\
$A_{2}$ & $3.88 \times 10^{18}$ & $6.83 \times 10^{15}$ & $7.81 \times 10^{17}$ & $1.68 \times 10^{19}$ & $5.37 \times 10^{18}$ & $7.80 \times 10^{18}$ \\
$E_{2}$ & 150 & 137 & 155 & 168 & 153 & 13 \\
$n_{2}$ & 3.40 & 1.62 & 1.40 & 1.56 & 1.99 & 0.94 \\
$A_{3}$ & $5.22 \times 10^{25}$ & $4.92 \times 10^{27}$ & $3.49 \times 10^{14}$ & $4.43 \times 10^{18}$ & $1.24 \times 10^{27}$ & $2.45 \times 10^{27}$ \\
$E_{3}$ & 223 & 242 & 138 & 174 & 194 & 47 \\
$n_{3}$ & 1.70 & 2.53 & 1.19 & 1.54 & 1.74 & 0.57 \\
$A_{4}$ & $1.11 \times 10^{9}$ & $4.10 \times 10^{5}$ & $1.11 \times 10^{5}$ & $3.65 \times 10^{3}$ & $2.78 \times 10^{8}$ & $5.55 \times 10^{8}$ \\
$E_{4}$ & 100 & 71 & 68 & 57 & 74 & 18 \\
$n_{4}$ & 0.85 & 0.89 & 0.60 & 0.40 & 0.69 & 0.23
\end{tabular}

${ }^{a} A_{\mathrm{i}}$ Pre-exponential factor for the $i$ th process $\left(\mathrm{s}^{-1}\right) .{ }^{b} E_{\mathrm{i}}$ Activation energy for the $i$ th process $\left(\mathrm{kJ}\right.$ mol ${ }^{-1}$ ). ${ }^{c} n_{\mathrm{i}}$ Reaction order for the $i$ th process.

In their study of the kinetics of polymerization of RTM6 (a polyfunctional epoxy resin comprising two aromatic amines), Partridge et al. reported ${ }^{23}$ that in order to fit their isothermal DSC data, it was necessary to use a modified kinetic model to account for both the early (kinetically controlled) and later (diffusion controlled) stages of reaction. It is striking that the activation energy for the later stages of the RTM6 cure mechanism has both an activation energy $\left(137 \mathrm{~kJ} \mathrm{~mol}^{-1}\right)$ and pre-exponential (collision) factor $\left(6.487 \times 10^{18} \mathrm{~s}^{-1}\right)$ that agree well with the parameters for the second process in the present study $\left(153 \mathrm{~kJ} \mathrm{~mol}^{-1}, 5.37 \times 10^{18} \mathrm{~s}^{-1}\right)$, implying that a similar mechanism might be responsible.
The Arrhenius parameters for the third (near second order) process (mean activation energy $194 \mathrm{~kJ} \mathrm{~mol}^{-1}$ ) are also unusually high and imply dissociation of a coordinated ligand (e.g. the primary aromatic amino nitrogen) followed by amineepoxy co-reaction. Finally, the highest temperature, near first order, process $\left(E_{4}=74 \mathrm{~kJ} \mathrm{~mol}^{-1}, A_{4}=2.78 \times 10^{8} \mathrm{~s}^{-1}\right)$ has parameters that are consistent with the figures recorded for a $\mathrm{BF}_{3}$-MEA-catalysed polyetherification. ${ }^{24}$

However, beyond inferring similarities on the basis of the magnitude of the parameters, it does not give a direct indication of the nature of the processes involved. Therefore, a further study of the polymerization process involving 

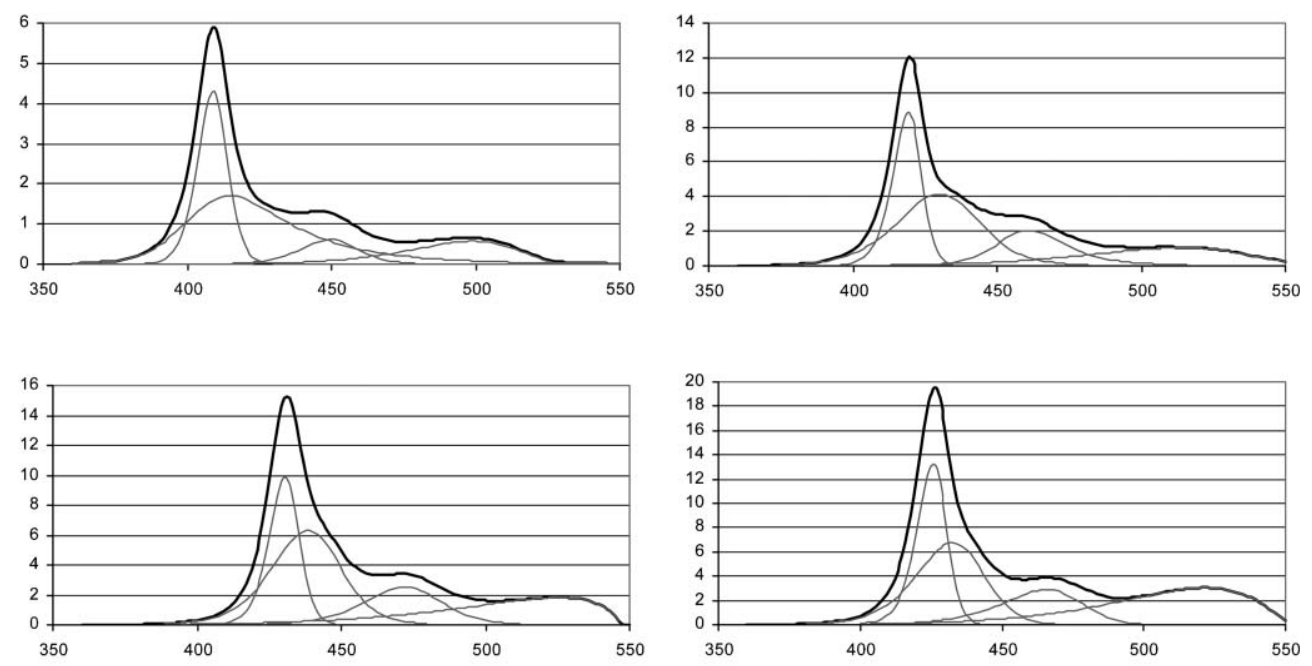

Temperature $(\mathrm{K})$

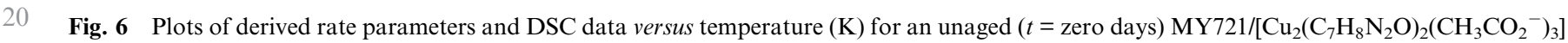
blend at different heating rates (clockwise from top left: $5 \mathrm{~K} \mathrm{~min}^{-1}, 10 \mathrm{~K} \mathrm{~min}^{-1}, 15 \mathrm{~K} \mathrm{~min}^{-1}, 20 \mathrm{~K} \mathrm{~min}{ }^{-1}$ ).

Table 5 Comparison of activation energy for the thermal polymerization of an $\mathrm{MY} 721 /\left[\mathrm{Cu}_{2}\left(\mathrm{C}_{7} \mathrm{H}_{8} \mathrm{~N}_{2} \mathrm{O}\right)_{2}\left(\mathrm{CH}_{3} \mathrm{CO}_{2}{ }^{-}\right)_{3}\right]$ formulation $($ at $t=$ zero days) with other epoxy resin systems

\begin{tabular}{|c|c|c|c|}
\hline Epoxy resin system & $E_{\mathrm{i}} / \mathrm{kJ} \mathrm{\textrm {mol } ^ { - 1 }}$ & $A_{\mathrm{i}} / \mathrm{s}^{-1}$ & Reference \\
\hline $\mathrm{MY} 721 /\left[\mathrm{Cu}_{2}\left(\mathrm{C}_{7} \mathrm{H}_{8} \mathrm{~N}_{2} \mathrm{O}\right)_{2}\left(\mathrm{CH}_{3} \mathrm{CO}_{2}^{-}\right)_{3}\right]$ & $\begin{array}{c}E_{1}=370 \\
E_{2}=153 \\
E_{3}=194 \\
E_{4}=74\end{array}$ & $\begin{array}{l}A_{1}=9.15 \times 10^{46} \\
A_{2}=5.37 \times 10^{18} \\
A_{3}=1.24 \times 10^{27} \\
A_{4}=2.78 \times 10^{8}\end{array}$ & $\begin{array}{l}- \\
- \\
-\end{array}$ \\
\hline MY720 & 172 & - & 25 \\
\hline MY720/DDS (100/100 pbw) & 73 & $4 \times 10^{4}$ & 24 \\
\hline MY721/DDS (100/27 pbw) & 75 & - & 26 \\
\hline RTM6 & $137^{a}$ & $6.487 \times 10^{18 b}$ & 22 \\
\hline DER332/DICY (1.0/0.9 equiv. $)^{c}$ & 101 & $3.96 \times 10^{9 d}$ & 22 \\
\hline
\end{tabular}

${ }^{a}$ Activation energy for the later, diffusion-controlled cure process(es) $\left(\mathrm{kJ} \mathrm{mol}{ }^{-1}\right) .{ }^{b}$ Pre-exponential factor for the later, diffusion-controlled

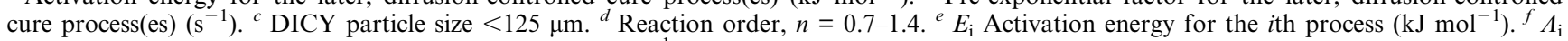
Pre-exponential factor for the $i$ th polymerization process $\left(\mathrm{s}^{-1}\right)$.

thermal NIR spectroscopy was carried out to verify the curing mechanism.

Spectroscopic examination of the cure mechanism of the epoxyl curing agent formulation

45 Variable temperature NIR spectroscopy was used to investigate the cure mechanism involving the complex, $\left[\mathrm{Cu}_{2}\left(\mathrm{C}_{7} \mathrm{H}_{8} \mathrm{~N}_{2} \mathrm{O}\right)_{2}\left(\mathrm{CH}_{3} \mathrm{CO}_{2}{ }^{-}\right)_{3}\right]$, and $\mathrm{MY} 721$ epoxy. In preparation for the experiment, individual NIR spectra were acquired for MY721, $\left[\mathrm{Cu}_{2}\left(\mathrm{C}_{7} \mathrm{H}_{8} \mathrm{~N}_{2} \mathrm{O}\right)_{2}\left(\mathrm{CH}_{3} \mathrm{CO}_{2}{ }^{-}\right)_{3}\right]$ and the $\mathrm{MY} 721 /\left[\mathrm{Cu}_{2}\left(\mathrm{C}_{7} \mathrm{H}_{8} \mathrm{~N}_{2} \mathrm{O}\right)_{2}\left(\mathrm{CH}_{3} \mathrm{CO}_{2}{ }^{-}\right)_{3}\right]$ blend (Fig. 7), from which the correspondence in signals is reasonably clear. On the basis of these assignments, a scanning experiment was performed during which individual spectra were acquired initially at $60{ }^{\circ} \mathrm{C}$ and thereafter at 2.5 hourly intervals (i.e. $15 \mathrm{~K}$ increments, equating to an instrumental heating rate of $0.1 \mathrm{~K} \mathrm{~min}^{-1}$ ) until $150{ }^{\circ} \mathrm{C}$, followed by a dwell period of an hour. The $t=$ zero spectrum is presented at the top of Fig. 8 and spectra representing the time course are depicted descending. There are distinct changes in the spectral region of $5500-6000 \mathrm{~cm}^{-1}$ : the bands associated with the first overtone of the terminal methylene and the fundamental stretching vibration of the epoxide are seen to diminish during cure. (The aromatic $\mathrm{CH}$ stretching first overtone bands are also observed in this region near $5980 \mathrm{~cm}^{-1}$ ). Perhaps more notably, there is a corresponding decrease in a complex series of bands at $c a .5000 \mathrm{~cm}^{-1}$ corresponding to the amine combination bands $(\mathrm{N}-\mathrm{H}$ asymmetric stretch and deformation); the prominent band at $4600 \mathrm{~cm}^{-1}$ also undergoes significant reduction during this period.

Examination of the thermal NIR spectral data also provided kinetic information for the process, although these are not directly comparable with the thermal analyses due to the disparity in heating rates (the spectroscopy experiments were conducted at a heating rate of $0.1 \mathrm{~K}$ minute ${ }^{-1}$ between glass microscope cover slips, whilst the slowest of the DSC experiments was conducted in sealed aluminium pans at $5 \mathrm{~K} \mathrm{minute}^{-1}$ ), there are obvious similarities. A comparison of the NIR transmission spectra of the pure MY721 and the cured mixture (Fig. 8) allows one to differentiate between the bands belonging to the epoxy and those arising from the 

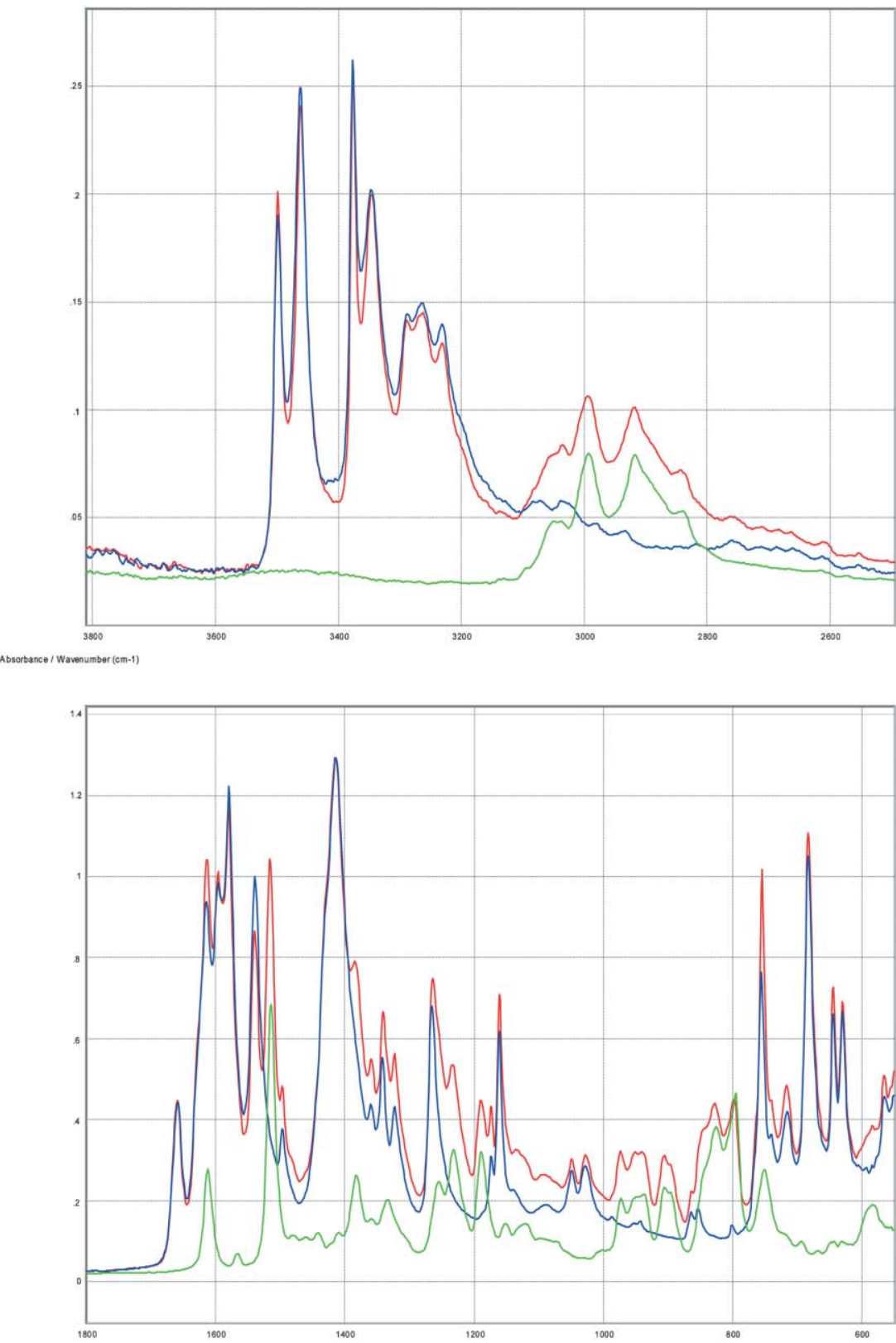

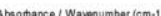

Fig. 7 Plots of near infrared transmission spectra of $\mathrm{MY} 721$ (green), $\left[\mathrm{Cu}_{2}\left(\mathrm{C}_{7} \mathrm{H}_{8} \mathrm{~N}_{2} \mathrm{O}\right)_{2}\left(\mathrm{CH}_{3} \mathrm{CO}_{2}{ }^{-}\right)_{3}\right] \quad(\mathrm{blue})$, and $\mathrm{MY}_{2} 1 /$ $\left[\mathrm{Cu}_{2}\left(\mathrm{C}_{7} \mathrm{H}_{8} \mathrm{~N}_{2} \mathrm{O}\right)_{2}\left(\mathrm{CH}_{3} \mathrm{CO}_{2}{ }^{-}\right)_{3}\right]$ blend (red).

incorporation of the curing agent (i.e. 6748, 5038, 4993 and $4947 \mathrm{~cm}^{-1}$ ). In each case, integration of the named band was normalised to the invariant aromatic combination band observed near $4620 \mathrm{~cm}^{-1}$.

It appears that different 'populations' are present in the spectral kinetic data: due to the epoxy and the curing agent (Fig. 9). Allowing for the fact that the oxirane intensity is presumably slightly affected by the large viscosity changes experienced during this period, the two epoxy bands appear to undergo little change until the temperature just exceeds $100^{\circ} \mathrm{C}$; the bands belonging to the curing agent behave very differently. At this stage the precise nature of the assignments is not clear from the spectra, but work is currently planned with model compounds to investigate the dissociation and curing mechanism.

\section{Conclusions}

A copper(II) complex, containing anthranilamide ligands, has been shown to display some measure of latent behaviour over a prolonged period of storage when formulated within a commercial epoxy resin. The storage stability of the complexes is slightly poorer than 2-aminobenzylamine (2-ABA) analogues and this is attributed to the lower degree of ligand complexation (i.e. the presence of free amido nitrogens is still able to initiate some polymerisation at ambient temperatures). 


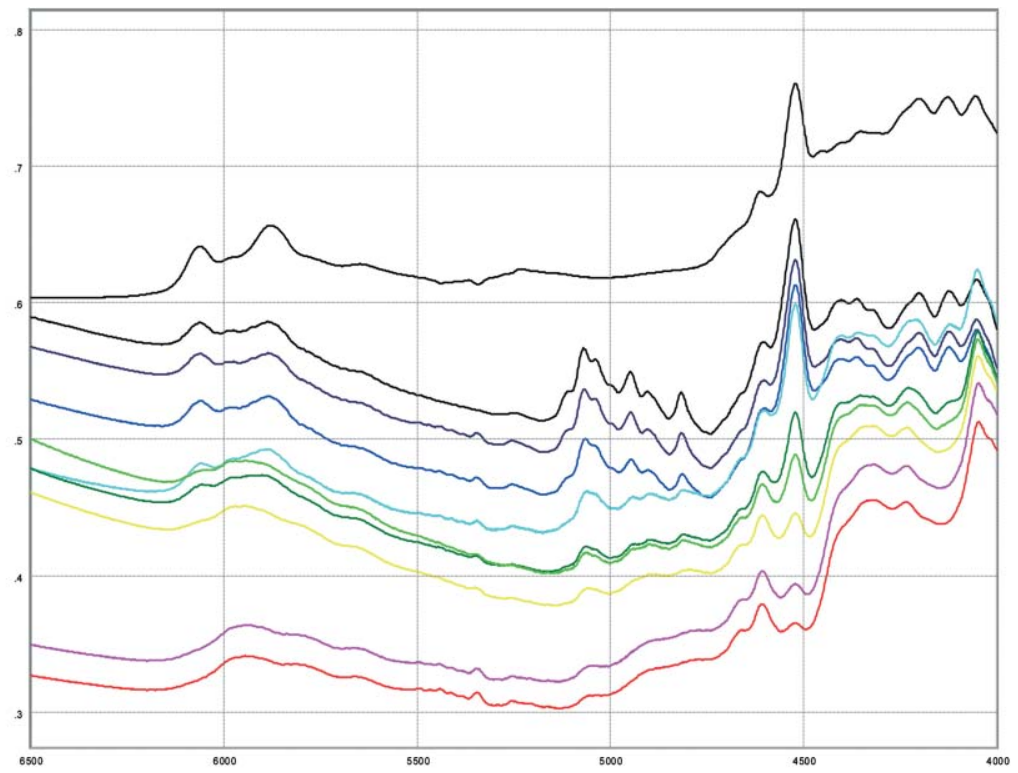

Fig. 8 Plots of near infrared transmission spectra of $\mathrm{MY} 721 /\left[\mathrm{Cu}_{2}\left(\mathrm{C}_{7} \mathrm{H}_{8} \mathrm{~N}_{2} \mathrm{O}\right)_{2}\left(\mathrm{CH}_{3} \mathrm{CO}_{2}{ }^{-}\right)_{3}\right]$ blend at time zero (top spectrum). Other spectra acquired at 2.5 hourly intervals (corresponding to $15 \mathrm{~K}$ ) starting at $60{ }^{\circ} \mathrm{C}$ and dwelling at $150{ }^{\circ} \mathrm{C}$.
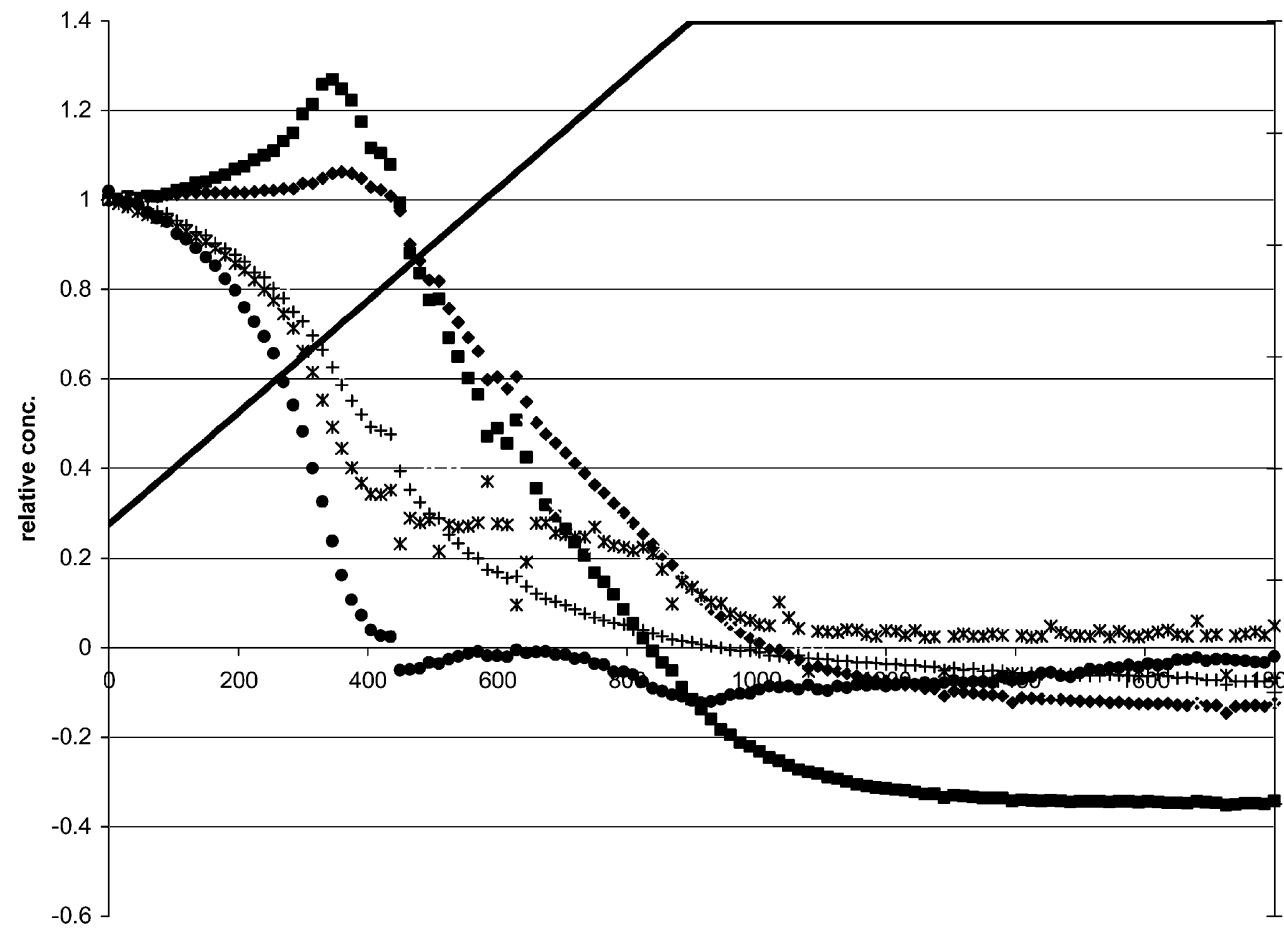

150

Fig. 9 Plots of selected (named) NIR bands within the MY721/[C $\left.\mathrm{Cu}_{2}\left(\mathrm{C}_{7} \mathrm{H}_{8} \mathrm{~N}_{2} \mathrm{O}\right)_{2}\left(\mathrm{CH}_{3} \mathrm{CO}_{2}{ }^{-}\right)_{3}\right]$ blend as a function of time and temperature, normalised to the aromatic combination band at $4620 \mathrm{~cm}^{-1}$.

Despite this observation, the latent storage behaviour is still impressive and the thermal dissociation of the free ligands, being less volatile than 2-ABA, no longer cause voids within the curing sample. The polymerisation of MY721 with the curing agent yields a polymer with a dry $T_{\mathrm{g}}$ of $128^{\circ} \mathrm{C}$. Kinetic analysis of the thermal polymerization of an MY721/ processes were sufficient to model the behaviour and the first (ca. second order) process has an unusually high activation energy ( $c a .370 \mathrm{~kJ} \mathrm{~mol}^{-1}$ ) suggesting both ligand dissociation and epoxy-amine cure. The parameters for the second process agree well with the later stages of the cure of RTM6, a commercial epoxy used for resin transfer moulding. The third ( $c$ a second order) process also has a high activation energy 
(ca. $194 \mathrm{~kJ} \mathrm{~mol}^{-1}$ ) and may also involve a second thermal dissociation step, whereas the final step appears to represent polyetherification. Work continues to examine the cure mechanism using model compounds.

\section{Acknowledgements}

This work was supported by Cytec-Fiberite, Ltd. (now Cytec Engineered Materials), Wrexham, in the form of a studentship (PJ). At the University of Surrey we thank Ms Nicola Walker for performing the elemental analyses.

\section{References}

1 An analysis of Plastics Consumption and Recovery in Western Europe 2003, APME, Brussels, 2004.

2 P. Michaud, Epoxy resins in composites: Business market survey, JEC Composites, October-November 2004, pp. 24-25 (http://www.huntsman.com/structural-composites/Media/ SC_EPOXY(BAT2)BUSINESSJCM12.pdf - accessed 1st March 2005).

3 W. R. Ashcroft, Curing agents for epoxy resins, in Chemistry and Technology of Epoxy Resins, ed. B. Ellis, Blackie Academic and Professional, Glasgow, p. 37.

4 R. Dowbenko, C. C. Anderson and W. H. Chang, UK Patent GB1204834, 1970.

5 I. Hamerton, B. J. Howlin and P. Jepson, Coord. Chem. Rev., 2002, 224, 67.

6 I. Hamerton, B. J. Howlin, J. R. Jones, S. Liu and J. M. Barton, Polymer, 1998, 39, 1929.

7 J. Brown, I. Hamerton and B. J. Howlin, J. Appl. Polym. Sci., 2000, 75, 201.
8 I. Hamerton, J. N. Hay, B. J. Howlin, P. Jepson and S. Mortimer, J. Appl. Polym. Sci., 2001, 80, 1489.

9 I. Hamerton, J. N. Hay, H. Herman, B. J. Howlin, P. Jepson and D. G. Gillies, J. Appl. Polym. Sci., 2002, 84, 2411.

10 J. R. Allan, B. McCloy, A. D. Paton, W. E. Smith and D. L. Gerrard, Thermochim. Acta, 1992, 205, 127.

11 J. R. Allan, B. McCloy and A. D. Paton, Thermochim. Acta, 1994, 231, 121.

12 W. Kemp, Organic Spectroscopy, Macmillan, London, 3rd edn., 1991, pp. 79

13 R. C. Weast and J. G. Grasselli, Handbook of Data on Organic Compounds, CRC Press, Boca Raton, 2nd edn., 1989, 1, A-Be.

14 D. Lin-Vien, N. B. Colthup, W. G. Fateley and J. G. Grasselli, The Handbook of Infrared and Raman Characteristic Frequencies of Organic Molecules, Academic Press, London, 1991, p. 143.

15 F. A. Cotton and G. Wilkinson, Advanced Inorganic Chemistry, John Wiley and Sons, Chichester, 4th edn., 1980, p. 755 and 741.

16 D. Kovala-Demertzi, J. M. Tsangaris and N. Hadjiliadis, Transition Met. Chem., 1983, 8, 140.

17 J. M. Barton, GB Patent 2135316, 1986.

18 H. Martens and T. Naes, Multivariate Calibration, John Wiley and Sons, Chichester, 1998.

19 I. Hamerton, H. Herman, A. K. Mudhar, A. Chaplin and S. J. Shaw, Polymer Commun., 2002, 43, 3381 .

20 I. Hamerton, A. M. Emsley, B. J. Howlin, P. Klewpatinond and S. Takeda, Polymer, 2003, 44, 4839.

21 I. Hamerton, A. M. Emsley, B. J. Howlin, P. Klewpatinond and S. Takeda, Polymer, 2004, 45, 2193.

22 E. Sacher, Polymer, 1973, 14, 91.

23 P. I. Karkanas, I. K. Partridge and D. Attwood, Polym. Int., 1996, 41, 183.

24 M. Tackie and G. C. Martin, J. Appl. Polym. Sci., 1993, 48, 793.

25 A. Apicella, L. Nicholais, M. Iaonnone and P. Passerini, J. Appl. Polym. Sci., 1984, 29, 2083.

26 G. A. George, G. A. Cash and L. Rintoul, Polym. Int., 1996, 41, 169.
1 


\section{Authors Queries}

Journal: Journal of Materials Chemistry

Paper: b510393b

Title: The development of controllable complex curing agents for epoxy resinsPart 3. An investigation of the shelf life and thermal dissociation behaviour of bis(acetanilido)-tris(acetato)dicuprate(II)

10 Editor's queries are marked like this... 1, and for your convenience line numbers are indicated like this... 5.

\begin{tabular}{|l|l|l|}
\hline $\begin{array}{l}\text { Query } \\
\text { Reference }\end{array}$ & Query & Remarks \\
\hline 1 & $\begin{array}{l}\text { I have changed the title to conform to house-style. } \\
\text { There is a footnote where Parts 1 and 2 must be } \\
\text { referenced. Which references would these be? If } \\
\text { they are not in the ref list, could you please add } \\
\text { them? Thanks. }\end{array}$ & $\begin{array}{l}\text { This reference is not cited in the text; please indicate } \\
\text { where you would like the citation to be added }\end{array}$ \\
\hline 2
\end{tabular}

